\title{
The Effect of Sport on the Level of Positivity and Well-Being in Adolescents Engaged in Sport Regularly
}

\author{
Yakup Bakır ${ }^{1}$, Murat Kangalgil ${ }^{2}$ \\ ${ }^{1}$ Physical Education Teacher, Ministry of Education, Samsun, Turkey \\ ${ }^{2}$ Physical Education Teaching Department, Cumhuriyet University, Sivas, Turkey \\ Correspondence: Murat Kangalgil, Physical Education Teaching Department, Cumhuriyet University, Turkey.
}

Received: August 13, 2017

doi:10.11114/jets.v5i11.2592
Accepted: October 10, $2017 \quad$ Online Published: October 16, 2017

URL: https://doi.org/10.11114/jets.v5i11.2592

\begin{abstract}
Sport, an element of universal culture, is a prominent tool that brings individuals with different languages, races and religions together. Sport is generally defined as activities that positively affect the psychological health of people and bring about social and moral benefits besides its physical benefits. Mental well-being is defined as the individual's awareness of their own abilities, their abilities to overcome stress in life, being productive and useful in business life and contributing to community via the their ability (WHO, 2004). Positivity is defined as the main determinant of subjective well-being and is expressed as a tendency to evaluate all aspects of life that is already good. This study aimed to investigate whether sport is effective on mental well-being and positivity. In the study pre-test, post-test experimental design with control group was used and "Warwick-Edinburgh Mental Well-being (WEMWBS)" scale developed by Tennant et al. (2007), which was adapted into Turkish by Keldal (2015) and "The Positivity Scale" scale developed by Caprara and et al. (2012), and adapted into Turkish by Çıkrıkçı, Çiftçi and Gençdoğan (2015) were used as the data collection tools. When the original form of mental wellbeing scale compared with its version adapted into Turkish are compared, the reliability coefficient Cronbach Alpha was found to be as .92. On the other hand, the internal consistency coefficient for the Positivity Scale was found to be .75 and its test-retest reliability coefficient was found to be .91 . As parametric assumptions are met, Variance Analysis, Tukey test, Paired-Samples t-test was used. For the analysis of data obtained through counting, Chi Square was used and level of significance was taken as 0.05 . The study group is composed by forming 3 groups of 20 students from 10th grade students. The groups were equalled in terms of some variables like age, gender, sports background etc. The groups were called as the sports activities group, social activities group and the control group. While the participants in the experimental group were engaged in regular and scheduled sports activities including training and contests, the participants in the social activities group engaged in regular social activities. The participants in the control group led their routine lives. After a period of 10 weeks, the tests given at the beginning of the study were administrated again, and test scores of the students in all three groups were compared.

According to the results of the study, when the pre-test and post-test positivity scores of the individuals in all three groups were compared, the differences between the groups were not found to be insignificant ( $p>0.05)$. When post-test mental well-being scores were compared, the difference was found significant $(\mathrm{p}<0.05)$. It was seen that the source of difference was between the sports activities group and the control group.

In terms of positivity scores, the difference between the pre-test and post-test scores of the sports activities group and the social activity group was found to be insignificant $(p>0.05)$. There was a decrease in the positivity scores of the control group from the pre-test to post-test and difference was found significant $(\mathrm{p}<0.05)$. When the pre-test and post-test mental well-being scores of the three groups were compared, the differences between measurements were found significant $(\mathrm{p}<0.05)$. While there was an increase in mental well-being scores of the sports activities group and of the social activities group, it was seen that there was a decrease in those of the control group. No significant difference was found in mental well-being and positivity scores of the participants in terms of gender and academic achievement ( $p>0.05)$.
\end{abstract}

Keywords: mental well-being, positivity, secondary education, adolescent

\section{Introduction}

Adolescence is an important period of human life and mental, physiological, psychological, social and cultural changes take place. There are many ways of relaxing this period, which is difficult for some people. One of them is doing social 
activities. Social activities are the name given to the activities that people make in order to pass their leisure time. It is important that social activities are done voluntarily. Social activities allow people to realize themselves. People feel comfortable and free thanks to it. People's doing the activities that comply with their family, their community and their culture will bring them substantial benefits (Alikaşifoğlu and Ercan, 2002). Social activities that start in the family or school are very important in the development of personality development and identity of adolescents. With social activities, adolescents have the opportunity to satisfy many emotions such as competition, responsibility and success. Another important aspect of social activity is that it prevents adolescents from turning to negative things in their free time. It allows young people to turn to activities which provide them benefits such as theatre, cinema, visiting museum, sport etc. instead of spending their free time for nothing or for things that can hurt them such as cigarette, alcohol etc. (Seçgin, 1996).

In terms of social activities, sport has a very important place and sports have many benefits in physiological, psychological and social sense. It is also known that the sport develops self-esteem, self-confidence, healthy communication, socialization and sense of belonging of individuals as well as its positive contributions to academic achievement (Balkaya, 2005). Sport is the means of establishing a social bond, and it allows children to develop the necessary feeling of belonging to a community. In the absence of this feeling, negative emotions such as anxiety, depression, loneliness, aggression and jealousy can develop in the individual (Medora et al., 1987; Asher and Paquette, 2003). Sports are very important in terms of protecting both the physiological and psychological health of people. From a psychological point of view, it increases the ability to cope with stressful situations by improving the self-esteem of the person. It also reduces mental stress by reducing depression and anxiety. All these effects social peace positively (Muratl1, 1997). For this reason, adolescents' engagement in activities that can make positive contributions, such as joining a sports team, is very important as it will contribute to their physiological, mental and social development (Alikaşifoğlu and Ercan, 2002). The activities will support mental well-being and positivity as they will make the person feel free from the stress and complexity of daily life and as they revive the feeling of doing something for themselves.

The concept of mental well-being is defined by the World Health Organization (WHO) as the ability of the individual to be aware of his or her own abilities, to be able to get over the stress in his life, to be productive and useful in his profession (WHO, 2004). According to another definition, mental well-being is defined as individual's feeling positive, being aware of his / her limits and enjoying himself / herself, trying to maintain relations based on warm and trust with other individuals, shaping the surroundings to meet the needs and desires of the individuals, being able to act freely and independently, having the meaning and aim of the life (Keyes, Shmotkin and Ryff, 2002). Researches have shown that individuals with higher levels of mental well-being have better psychological and physical health and higher quality of life (Keyes, 2002; Keyes, Dhingra and Simoes, 2010). In terms of mental well-being, the most important thing to benefit one is the support from outside the family as well and at this point sports activities are one of the most important elements that provide this benefit. Sport is a very important field where individuals are in contact with a large number of people, and they develop different ties. Sport also prevents people from being withdrawn. Because of the sports, extravert adolescents become very active by engaging in a variety of physical activities, and the award they receive increases their mental well-being. At the same time, as introvert adolescents have negative emotions and extravert adolescents have positive emotions, extravert adolescents have a lot better mental health (Gün, 2006). One of the mental well-being elements is happiness. Mental well-being is measured based on individuals' psychological and sociological activities, life pleasure and satisfaction (Şenduran, 2008).

Nowadays positivity, which is another concept, has a significant place in the human life. In the past, while positivity in society was primarily accepted in connection with physical well-being, the data obtained from recent clinical research have shown that physical and psychological health have a positive relationship. But in modern societies personal health is a more comprehensive understanding, including being positive. Positivity, which is defined as having positive tendency or positive thinking, corresponds to the latent dimension underlying life satisfaction, self-esteem and optimism affected by the cognition, emotions and actions of people. Positivity means that individuals have a positive orientation or positive evaluation towards the self, the future and past experiences (Yıldız, 2016). According to these definitions of researchers, it can be said that people's evaluation of themselves corresponds to self-esteem, evaluation of their own life corresponds to life satisfaction and evaluation of future corresponds to optimism (Alessandri et al., 2012). Unlike the concept of negativity, which is commonly defined as generally having negative feelings and malfunction of life, positivity reflects the positive sides of people with welfare and practicality (Keyes and Annas, 2009). The concept of positivity is examined as a three-dimensional phenomenon. One of these dimensions includes positive subjective experiences such as happiness, the feelings about the current and the past experiences, satisfaction, joy, flow, self-fulfillment. Feelings like hope and faith are prospective feelings. Positivity in such feelings make life more qualified. In the second dimension, there are positive personal qualities such as love, job satisfaction, courage, 
self-sacrifice, forgiveness, self-management, originality, self-respect and wisdom. These qualities are also regarded as essential qualities of a good character at the same time. In the last dimension are positive qualities composed of positive experiences and qualifications developing as a result of taking office, self-sacrifice, support, kindness, agreement, tolerance and work ethic (Fineman, 2006). In the light of all this information, in this study aims to investigate whether doing sport are effective on the concepts of mental well-being and positivity in adolescents. In addition, the findings of the study will be helpful for teachers and parents as well as adolescents.

\section{Method}

\subsection{Study Group}

In this study, 60 students from Sivas/Zara Science High School 10th grade students, who were equal for other variables, were chosen as the sample. In the study, 3 groups, who were equal in terms of some variables (age, gender, sports background etc.), were created from the 10th grade students. They are named as the sports activity group, the social activity group, and the control group. Regular and scheduled sports activities were organized for the sports activities group ( 2 hours per 2 days a week for 10 weeks). These activities included training and competitions. The second group was involved in social activities (cinema, theatre, sightseeing, picnic, attending live music performance, collective games, etc.) at regular intervals ( 2 hours per 2 days a week for 10 weeks). The third group, the control group, lead their life as usual. At the end of the 10-week period, the pre-tests were re-administered to the students and the test scores of the sportsmen and the other students were compared.

\subsection{Data Collection Tools}

In the study, "Warwick-Edinburgh Mental Well-being Scale" (WEMWBS) scale, which was developed by Tennant et al. (2007), adapted into Turkish by Keldal (2015) and "The Positivity Scale" scale which was developed by Caprara et al. (2012), adapted into Turkish by Çıkrıkçı, Çiftçi and Gençdoğan (2015) were used as data collection tools. The Mental Well-Being Scale consists of 14 positive items with 5-Likert-type choices. The minimum score, which can be taken, is 14 and the maximum score is 70. High scores on the scale indicate high mental well-being. As a result of explanatory factor analysis to determine reliability of the scale, it was seen that it explains a large part of total variance. When the original form of mental well-being scale compared with its version adapted into Turkish, the reliability coefficient (Cronbach Alfa $=.92$ ) was seen to be high. The original form of the positivity scale has a five-point likert-type rating. The positivity scale consists of eight items, one of which is reverse-scored. Minimum 8 and maximum 40 points can be taken from the measurement tool. Higher scores indicate that the individual's positivity level is higher. As a result of the exploratory factor analysis, a one-factor structure, which accounts for $47.58 \%$ of the total variance, was obtained.

\subsection{Analysis of Data}

In the evaluation of the data obtained in the study, variance analysis, Tukey test, paired sample t-test were used and the level of error was taken as .05 .

\section{Results}

Table 1. Comparison of Positivity Pre-Test and Post-Test, and Mental Well-Being Pre-Test and Post-Test Scores of the Students in All Three Groups

\begin{tabular}{llllllll}
\hline & Group & $\mathrm{N}$ & Mean & Sd. & Min. & Max. & Result \\
\hline Positivity & Sports & 20 & 30.40 & 3.16 & 24.00 & 36.00 & $\mathrm{~F}=0.01$ \\
pre-test & Social & 20 & 30.40 & 4.13 & 21.00 & 37.00 & $\mathrm{P}=0.99$ \\
& Control & 20 & 30.45 & 3.21 & 24.00 & 39.00 & \\
Positivity & Sports & 20 & 30.55 & 2.28 & 26.00 & 34.00 & $\mathrm{~F}=0.37$ \\
post-test & Social & 20 & 30.55 & 3.15 & 22.00 & 36.00 & $\mathrm{P}=0.68$ \\
& Control & 20 & 29.85 & 3.29 & 23.00 & 38.00 & \\
Mental & Sports & 20 & 54.85 & 5.20 & 45.00 & 64.00 & $\mathrm{~F}=0.29$ \\
Well-being Pre-Test & Social & 20 & 54.05 & 6.62 & 37.00 & 65.00 & $\mathrm{P}=0.74$ \\
Mental & Control & 20 & 53.35 & 6.55 & 36.00 & 64.00 & \\
Well-being Post-test & Sports & 20 & 57.85 & 4.22 & 50.00 & 65.00 & $\mathrm{~F}=5.14$ \\
& Social & 20 & 56.40 & 5.28 & 44.00 & 65.00 & $\mathrm{P}=0.009^{*}$ \\
\hline
\end{tabular}

*p $<0.05$

According to Table 1, when the positivity pre-test and post-test and mental well-being pre-test scores of individuals in all three groups are compared with each other, the differences between the groups were not found significant ( $>>0.05)$, but when the mental well-being post-test scores are compared, the differences between the groups were found significant $(\mathrm{p}<0.05)$. This difference was found between the control group and the sports activities group. 
Table 2. Comparison of Positivity Pre-Test and Post-Test Scores of the Students in All Three Groups

\begin{tabular}{llllll}
\hline Group & Measurement & Mean & $\mathrm{N}$ & $\mathrm{Sd}$ & $\mathrm{Result}$ \\
\hline Sports & Positivity Pre-Test & 30.40 & 20 & 3.16 & $\mathrm{t}=0.30$ \\
& Positivity Post-Test & 30.55 & 20 & 2.28 & $\mathrm{P}=0.76$ \\
Social & Positivity Pre-Test & 30.40 & 20 & 4.13 & $\mathrm{t}=0.42$ \\
& Positivity Post-Test & 30.55 & 20 & 3.15 & $\mathrm{P}=0.67$ \\
Control & Positivity Pre-Test & 30.45 & 20 & 3.21 & $\mathrm{t}=3.04$ \\
& Positivity Post-Test & 29.85 & 20 & 3.29 & $\mathrm{P}=0.007 *$ \\
\hline
\end{tabular}

$* \mathrm{p}<0.05$

According to Table 2, when the positivity pre-test and post-test scores of individuals in all three groups were compared, the difference between sports activity group and social activity groups positivity levels on the pre-test and post-test were not found significant $(\mathrm{p}>0.05)$. Difference between pre-test and post-test scores of individuals in the control group is significant $(\mathrm{p}<0.05)$ and this difference was determined due to the decrease in post-test positivity scores.

Table 3. Comparison of Mental Well-Being Pre-Test and Post-Test Scores of the Students in all Three Groups

\begin{tabular}{llllll}
\hline Group & Measurement & Mean & $\mathrm{N}$ & $\mathrm{Sd}$ & $\mathrm{Result}$ \\
\hline Sports & Mental Well-Being Pre-Test & 54.85 & 20 & 5.20 & $\mathrm{t}=6.45$ \\
& Mental Well-Being Post-Test & 57.85 & 20 & 4.22 & $\mathrm{P}=0.001^{*}$ \\
Social & Mental Well-Being Pre-Test & 54.05 & 20 & 6.62 & $\mathrm{t}=5.61$ \\
& Mental Well-Being Post-Test & 56.40 & 20 & 5.28 & $\mathrm{P}=0.001^{*}$ \\
\multirow{3}{*}{ Control } & Mental Well-Being Pre-Test & 53.35 & 20 & 6.55 & $\mathrm{t}=2.26$ \\
& Mental Well-Being Post-Test & 52.60 & 20 & 6.32 & $\mathrm{P}=0.036^{*}$ \\
\hline 0.05 & & & & &
\end{tabular}

According to Table 3, When Mental Well-Being Pre-test and Post-test scores of individuals in all three groups are compared, the difference is significant $(\mathrm{p}<0.05)$. According to the results, while there was an increase in the sports activities group and social activity groups mental well-being scores, there was a decrease in mental well-being scores of the control group.

Table 4. Comparison of Success Situations of Students Participating the Study

\begin{tabular}{lllllll}
\hline Group & $\mathrm{N}$ & Mean & Sd. & Min. & Max. & Result \\
\hline Sports & 20 & 78.77 & 4.09 & 71.02 & 86.30 & \multirow{F}{*}{$=1.72$} \\
Social & 20 & 76.64 & 7.70 & 59.80 & 87.62 & $\mathrm{P}=0.18$ \\
Control & 20 & 74.74 & 8.07 & 58.93 & 85.75 & \\
\hline
\end{tabular}

According to Table 4, when the academic achievements of the students in all three groups were compared, the difference between the groups was not found significant $(\mathrm{p}>0.05)$.

Table 5. Comparison of Mental Well-Being and Positivity Scores of the Individuals in All Three Groups According to Gender

\begin{tabular}{lllllll}
\hline Group & Measurement & Gender & $\mathrm{N}$ & Mean & $\mathrm{Sd}$ & Result \\
\hline \multirow{5}{*}{ Sports } & Positivity & Female & 10 & 30.70 & 2.16 & $\mathrm{t}=0,27$ \\
& Mental & Male & 10 & 30.40 & 2.50 & $\mathrm{P}=0,786$ \\
& Well-Being & Female & 10 & 58.70 & 4.27 & $\mathrm{t}=0,89$ \\
& Male & 10 & 57.00 & 4.21 & $\mathrm{P}=0,382$ \\
\multirow{5}{*}{ Social } & Positivity & Female & 10 & 30.90 & 4.20 & $\mathrm{t}=0,48$ \\
& Mental & Male & 10 & 30.20 & 1.75 & $\mathrm{P}=0,633$ \\
& Well-Being & Female & 10 & 56.30 & 7.28 & $\mathrm{t}=0,08$ \\
& Pale & 10 & 56.50 & 2.41 & $\mathrm{P}=0,933$ \\
Control & Mental & Memale & 10 & 30.50 & 3.37 & $\mathrm{t}=0,87$ \\
& Mell-being & Female & 10 & 51.30 & 5.39 & $\mathrm{P}=0,392$ \\
& Male & 10 & 53.90 & 7.18 & $\mathrm{t}=0,92$ \\
\hline
\end{tabular}

According to Table 5, when the positivity and mental well-being scores of the students in all three groups were compared, the difference between the groups was not found significant $(\mathrm{p}>0.05)$. 


\section{Discussion}

In the study, when positivity pre-test and post-test and mental well-being pre-test scores of the all three group were compared to determine the effects of regular sports activities and social activities on mental well-being and positivity, the difference between the groups was not found significant ( $p>0.05$ ). But the difference between mental well-being post-test scores of the groups was found significant $(\mathrm{p}<0.05)$. This difference is found between the control group and the sports activities group. When the literature is examined, it is noteworthy that healthy physical activity positively affects mental health and quality of life (Ekkekakis and Backhouse, 2014) because sport makes it possible for sport-doing people to experience themselves, to compare themselves with peers and to compete in a positive environment. All these factors stated strengthen positive self-esteem, positive personality perception and increase mental strength (Malina, 1996; Weiss, 1993; Sahin et al, 2012). When evaluated in this respect, it can be said that it is a result supporting the hypothesis and consistent with the literature.

In the study, when the positivity pre-test and post-test scores of the individuals in all three groups were compared, while the difference between pre-test and post-test of positivity levels of the sports activities group and the social activities groups was not found significant ( $>0.05$ ), the difference between the pre-test and post-test scores of individuals in the control group was found significant $(\mathrm{p}<0.05)$. Although it is known that the endorphin is increasing with sport and physical activities, brings relaxation and calmness and thus reduces stress hormones (Allen and Coen, 1987). In our research findings, the difference between the sports activities and social activity groups' were not found significant. However, there is no literature finding that can explain the significant decrease in the post-test positivity scores of the control group.

In the study, when the mental well-being pre-test and post-test scores of individuals in all three groups were compared, the difference between the scores was found significant $(\mathrm{p}<0.05)$. According to the results, while there was an increase in the mental well-being scores of the sports activity and social activity groups, there was a decrease in the mental well-being scores of the control group. When the literature is examined, individual's satisfaction with his/her social relations, existence of social elements that can please the individual and sincere relationships contribute individuals' feeling safety (Diener and Fujita, 1995). The social activities attended by the students are very important for their development. Having close relations with people, participating in an art activity (theatre, cinema, concert, etc.), visiting places where they can discover new things and doing things they like make individuals happy. It is known that happiness will benefit both psychologically and physiologically because a happy person has a high life quality (Ho et al., 2016). In our study, no finding was found in the literature that can explain the decline in post-test positivity scores in the control group.

In the study, when the academic achievements of the students in all three groups were compared, the difference was not found significant ( $>0.05$ ). When the literature is examined, Aksoy's (1999) study seems to have found a positive direct link between academic achievement and sport participation in the school. According to the study, it was seen that the individuals involved in sports activities were abstracted from the lessons and more efficient in situations where they are required to attend the lesson. In Aykaç's (2007) study, it is pointed out that the free time activities have a positive direct link with the academic achievement in the school and taking part in sporting events resulted in increase in school success of the students. In Singh et al.,'s (2012) study, it is seen that the students, who are physically more active, have a higher academic achievement and there is a positive relationship between physical activities and academic achievement. In Tosun et al.,'s (2015) study in which the relation between sports-and success and motivation of college students was examined, it was determined that the students who were more active physically had higher academic achievements. In a study by Er (2010), it was concluded that the sport, which is effective in psychological, social, cultural and behavioral development besides its contribution to physical development of individuals engaged in regular sport activities, also positively affects academic achievement. These results do not comply with our findings.

In the study, when the positivity and mental well-being scores of the students in all three groups according to gender were compared, the difference between the groups was not found significant ( $p>0.05)$. The studies examining the discrimination between women and men in terms of mental well-being are contradictory. While Haring et al., (1984) concluded that men are more advanced than women in terms of mental well-being, Ryff et al., (1999) found that women were better than men. Diener, Myers and Lucas (1995) emphasize equality between men and women in positivity. In other words, there is no mention of a significant effect of gender on positivity. When the results of previous studies are considered, it can be said that the result of this study related to the gender in the study are in accordance with the literature.

In conclusion, in line with findings related to mental well-being and positivity, it is of great importance for children to increase the sociability together with feasible physical activity programs. It can be argued that mental well-being and positivity levels of individuals who are engaged in physical activity and scheduled sports programs increase while their 
negative feelings in negative emotions and thus, these activities are important to overcome the adolescence period more comfortably with less problems.

* This study is a part of the Master Thesis and presented in the Congress of International Educational Research (Ordu University, 11-14 May 2017).

** This study is supported by the Scientific Research Project Fund of Cumhuriyet University under the project number BED-017.

\section{References}

Aksoy, C. (1999). Educational Effect of Physical Education and Sports. (Unpublished master thesis). İnönü University, Malatya, Turkey

Alessandri, G., Caprara, G. V., \& Tisak, J. (2012). The Unique Contribution of Positive Orientation to Optimal Functioning. European Psychologist, 17, 44-54. https://doi.org/10.1027/1016-9040/a000070

Alikaşifoğlu, M., \& Ercan, O. (2002). Drug Use Among Adolescents. Turkish Pediatrics Archives, 37, 66-73.

Allen, M. E., \& Coen, D. (1987). Naloxone-Blocking Of Running-Induced Mood Changes. Annals of Sport Medicine, 3, $190-195$.

Asher, S. R., \& Paquette, J. A. (2003). Loneliness and Peer Relations in Childhood. Current Directions in Psychological Science, 12, 75-78. https://doi.org/10.1111/1467-8721.01233

Aykaç, T. (2007). The Effetcts of the Recreative Activities to the Anxiety Level of The Primary School 7th and 8th Grade Students and Their Academical Success (Model of KocaeliGölcük). (Unpublished Master Thesis). Kocaeli University, Kocaeli, Turkey

Balkaya, A. (2005). Investigation the Levels of Sense of Identity Acquisition of High School Students Through Some Personal-Social and Parental Characteristics Along With the Level of Crime Behavior (Unpublished Master Thesis). Anadolu University, Eskişehir, Turkey

Caprara, G. V., Alessandri, G., \& Eisenberg, N. (2012). Prosociality: the Contribution of Traits, Values, and Self-Efficacy Beliefs. Journal of Personality and Social Psychology, 102, 1289-1303. https://doi.org/10.1037/a0025626

Çıkrıkçı, Ö., Çiftçi, M., \& Gençdoğan, G. (2015).The Psychometric Properties of the Turkish Form of the Positivity Scale.The Journal of Happiness \& Well-Being, 3(1), 57-76.

Diener, E., \& Fujita, F. (1995). Resources, Personal Strivings and Subjective Well- Being: A Nomothetic And Idiographic Approach. Journal of Personality and Social Psychology, 68, 926-935. https://doi.org/10.1037/0022-3514.68.5.926

Diener, E., Myers, S., \& Lucas, R. E. (1995). Personality, Culture and Subjective Well Being: Emotional and Cognitive Evaluations of Life. Annual Review Psychology, 54, 403-425. https://doi.org/10.1146/annurev.psych.54.101601.145056

Ekkekakis, P., \& Backhouse, S. H. (2014). Physical Activity and Feeling Good. (Chapter 44. In: Papaioannou AG, Hacjfort D, Eds.) Routledge Companion to Sport and Exercise Psychology. Routledge, 687-704.

Er, F. (2010). Comparison of Relationship Between Physical Fitness Levels and Academic Success of University Students Regularly and Not Regularly Sporting. (Unpublished Master Thesis). Gazi University, Ankara, Turkey

Fineman, S. (2006). On Being Positive: Concerns And Counterpoints, Academy of Management Review, 31(2), 270-291. https://doi.org/10.5465/AMR.2006.20208680

Gün, E. (2006). Self Esteem in Adolescents Who Do Sport and Who Do Not (Unpublished Master Thesis). Çukurova University, Adana, Turkey

Haring, M. J., Stock, W. A., \& Okun, M. A. (1984). A Research Synthesis of Gender and Social Class as Correlates of Subjective Wellbeing. Human Relations, 37, 645-657. https://doi.org/10.1177/001872678403700805

Ho, R. T., Fong, T. C., Wan, A. H., Au-Yeung, F. S., Wong, C. P., Ng, W. Y.,... Chan, E. Y. (2016). A Randomized Controlled Trial on The Psychophysiological Effects of Physical Exercise ond Tai-Chi in Patients with Chronic Schizophrenia. Schizophrenia Research, 171, 42-49. https://doi.org/10.1016/j.schres.2016.01.038

Keldal, G. (2015). Turkish Version of the Warwick-Edinburgh Mental Well-Being Scale: A Validity and Reliability Study. The Journal of Happiness \& Well-Being, 3(1), 103-115.

Keyes, C. L. (2002). The Mental Health Continuum: From Languishing to Flourishing in Life. Journal of Health and Social Behavior, 43, 207-222. https://doi.org/10.2307/3090197 
Keyes, C. L. M., \& Annas, J. (2009). Feeling Good and Functioning Well: Distinctive Concepts in Ancient Philosophy and Contemporary Science. The Journal of Positive Psychology, 4(3), 197-201. https://doi.org/10.1080/17439760902844228

Keyes, C. L. M., Shmotkin, D., \& Ryff, C. D. (2002). Optimizing Well-Being: The Empirical Encounter of Two Traditions. Journal of Personality and Social Psychology, 82(6), 1007-1023. https://doi.org/10.1037/0022-3514.82.6.1007

Keyes. C. L., Dhingra, S. S., \& Simoes, E. J. (2010). Change in Level of Positive Mental Health as a Predictor of Future Risk of Mental Illness. American Journal of Public Health, 100, 2366-2371. https://doi.org/10.2105/AJPH.2010.192245

Malina R. (1996). The Young Athlete: Biological Growth and Maturation in a Biosocial Context. In: Smoll F, Smith R (Eds). Children and Youth in Sports: A Biosocial Perspective: Brown and Benchmark; 161-186.

Medora, N., Woodward, J., \& Larson, J. (1987). Adolescent Loneliness: A Cross-Cultural Comparison Of Americans And Asian Indians. International Journal of Comparative Sociology, 28, 204-210. https://doi.org/10.1177/002071528702800306

Muratl1, S. (1997). Children and Sports. Bağırgan Publishing, Ankara.

Ryff C. D., Magee, J. W., Kling, C. K., \& Wing, H. E. (1999). Forging Macro-Micro Linkages in the Study of Psychological Well-Being, The Self and Society in Aging Procesess, (Ed. Ryff C.D., Magee, J.W.), Springer Publishing Company, New York, pp. 247-278.

Seçgin, H. (1996). Determination of the Porfits of Extra-Curricular Activities to Evaluation of Leisure in Secondary Education (Unpublished Doctoral Thesis). Dokuz Eylül University, İzmir, Turkey

Singh, A., Uijtdewilligen, L., Twisk, J. W., Van Mechelen, W., \& Chinapaw, M. J. (2012). Physical Activity and Performance at School: A Systematic Review of the Literature Including a Methodological Quality Assessment. Archives of Pediatrics and Adolescent Medicine, 166(1), 49-55. https://doi.org/10.1001/archpediatrics.2011.716

Şahin, M., Yetim, A. A., \& Çelik, A. (2012). Physical Activity and Sport as a Preventive Factor in Building Resilience. The Journal of Academic Social Science Studies, 5(8), 373-380.

Şenduran, F. (2008). Adaptation Skills of High School Students Who Are Sportsmen and Who Are Not.10th International Sport Sciences Congress. Oral presentations Book. October, 23-25.Bolu, Turkey

Tennant, R., Hiller, L., Fishwick, R., Platt, S., Joseph, S., Weich, S., ... Stewart-Brown, S. (2007). The Warwick-Edinburgh mental well-being scale (WEMWBS): Development and UK validation. Health and Quality of Life Outcomes, 5(1), 50-63. https://doi.org/10.1186/1477-7525-5-63

Tosun, A., Demir, B., Uçkun, G., \& Konak, O. (2015). Relationship of Sports Activities to the Success and Motivation of University Students. Relationship of Sports Activities to the Success and Motivation of University Students. $4^{\text {th }}$ International Vocational Schools Symposium, Vol 2. Yalova, Turkey

Weiss M. R. (1993). Psychological Effects of Intensive Sport Participation on Children and Youth: Selfesteem and Motivation. In: Cahill BR, Pearl AJ (Eds). Intensive Participation in Children's Sports. Champaign (IL): Human Kinetics; 39-70.

World Health Organisation. (2004). Promoting Mental Health; Concepts Emerging Evidence and Practice (Summary report). Geneva.

Yıldız, M. A. (2016). Multiple Mediation of Emotion Regulation Strategies in the Relationship Between Loneliness and Positivity in Adolescents. Education and Science, 41, 217-231. https://doi.org/10.15390/EB.2016.6193

\section{Copyrights}

Copyright for this article is retained by the author(s), with first publication rights granted to the journal.

This is an open-access article distributed under the terms and conditions of the Creative Commons Attribution license which permits unrestricted use, distribution, and reproduction in any medium, provided the original work is properly cited. 